\title{
Effects of controlled burn rice husk ash on the geotechnical properties of soil
}

\author{
Najmun Nahar, ${ }^{1,2}$ Alex Otieno Owino, ${ }^{1}$ Sayful Kabir Khan,,${ }^{1,3}$ Zakaria Hossain, ${ }^{1}$ Noma Tamaki ${ }^{4}$ \\ ${ }^{1}$ Department of Environmental Science and Technology, Graduate School of Bioresources, Mie University, Tsu, Japan; \\ ${ }^{2}$ Department of Geography and Environment, Faculty of Life and Earth Science, Jagannath University, Dhaka, \\ Bangladesh; ${ }^{3}$ Ministry of Food, Dhaka, Bangladesh; ${ }^{4}$ Make Integrated Technology Company, Osaka, Japan
}

\begin{abstract}
Pozzolanic reactions of rice husk ash (RHA) entirely depend on controlled burning condition. The current study illustrates the effects of controlled burn RHA on the geotechnical properties of A-2-4 soil as per the American Association of State Highway and Transportations Officials (AASHTO) classification. The compactibility, bearing capacity, compressive strength, shear strength, and scanning electron micrographs were investigated as the important geotechnical properties of soil with $0 \%, 5 \%, 10 \%$, and $15 \%$ of RHA admixtures considering the 7-day moist curing. The test results showed that the optimum moisture content increased, but maximum dry density reduced with the increment of RHA content. Soil with 5\% RHA showed the increased percentage of California bearing ratio (39.5\%), unconfined compressive strength $(6.0 \%)$, modulus of deformation $(56.3 \%)$, cohesion $(11.8 \%)$, and angle of internal friction (6.3\%) compared to untreated soil specimen which indicated that the application of burnt RHA at a controlled temperature enhanced the geotechnical properties of soil. Scanning electron microscopy image on soil with 5\% RHA also observed the best microstructural development, which recom-
\end{abstract}

Correspondence: Najmun Nahar, Department of Environmental Science and Technology, Graduate School of Bioresources, Mie University, Tsu, Japan. E-mail: najmun_nahar33@yahoo.com

Key words: Rice husk ash; compactability; unconfined compressive strength; bearing capacity; shear strength; scanning electron micrograph.

Acknowledgements: the authors would like to acknowledge the Ministry of Education, Culture, Sports, Science and Technology, Japan, provided by the MEXT scholarship in Mie University for the research.

Contributions: NN, methodology, data curation and original draft writing; AOW, manuscript review, and editing; SKK, data curation; ZH, supervisor of the Ph.D. student, funding acquisition, and research coordination.

Received for publication: 13 June 2021.

Accepted for publication: 15 September 2021.

(C) Copyright: the Author(s), 2021

Licensee PAGEPress, Italy

Journal of Agricultural Engineering 2021; LII:1216

doi:10.4081/jae.2021.1216

This article is distributed under the terms of the Creative Commons Attribution Noncommercial License (by-nc 4.0) which permits any noncommercial use, distribution, and reproduction in any medium, provided the original author(s) and source are credited. mends that soil with 5\% RHA can be used as a construction material for rural roads and pedestrian roads.

\section{Introduction}

Rice husk ash (RHA), a natural carbon-based agricultural byproduct, contains the highest amorphous silica among all agricultural wastes (Thomas, 2018). It has pozzolanic properties with a large specific surface, reacting with soil as secondary cementitious materials in the soil stabilization process (Sarkar et al., 2012). It is produced from paddy rice by milling process as rice husk and then formed as ash by burning process (Pode, 2016). The paddy rice production was 782 million tons worldwide in 2018 (FAOSTAT, 2020), and about 172 million tons of rice husk and 34 million tons of RHA were produced from the paddy rice in that year (Nahar et al., 2021). The chemical composition, particle size, pozzolanic reactivity, and silica state in RHA entirely rely on the burning conditions, temperature, and duration (Hwang and Chandra, 1996; Singh, 2018). Silica content in RHA shows the amorphous and crystalline state with different properties (Della, 2002). Crystalline silica is produced by uncontrolled burning or open burning of rice husk at a temperature above $800^{\circ} \mathrm{C}$, which are low reactive or non-reactive silica minerals (Singh, 2018). On the other hand, amorphous silica is the best for pozzolanic reaction, formed by the controlled temperature at $600^{\circ} \mathrm{C}-700^{\circ} \mathrm{C}$ (Hwang and Chandra, 1996). The amorphous silica of well-burnt RHA in single-phase displayed a halo pattern with a peak at around $2 \theta=22^{\circ}$ by the X-ray diffraction (XRD) test (Chandrasekhar et al., 2003; Al-Hasnawi and Al-Hydary, 2019; Nahar et al., 2021).

RHA waste creates environmental and health problems because of its disposal difficulties and absence of utilization (Pode, 2016). Concurrently, suitable construction sites are deficient due to rapid urbanization and industrialization, demanding feasible ground improvement techniques for untreated soil (Murthy et al., 2002). The strength and durability of engineering structures are affected by the geotechnical properties of soil (Roy and Bhalla, 2017). The usage of various chemical additives is one of the effective methods for improving the geotechnical properties of soil (Adhikary and Jana, 2016). Many researchers have discovered that adequately utilizing locally obtainable RHA as a pozzolanic material in ground improvement can decrease environmental degradation and construction price and increase soil strength properties (Alhassan, 2008; Jain et al., 2020). Several studies have been conducted on soil with only RHA in ground improvement. Among these investigations, only Sarkar et al. (2012) and Ayininuola and Olaosebikan (2013) used the controlled burn and as-obtained RHA for soil stabilization. However, Rahman et al. (2014) and Rathan et al. (2016) took the uncontrolled burn and natural RHA; Alhassan (2008), Okafor and Okonkwo (2009), and Adhikary and Jana (2016) utilized the 
uncontrolled burn, ground, and sieved (by No. 200) RHA, but Jain et al. (2020) used the pulverized and sieved RHA by No. 4 sieve for soil improvement. Grinding is essential for open burnt RHA to attain the fineness and large specific surface area of RHA that can provide the best pozzolanic reactions, but it needs extra time and costs. The cost of producing RHA at a controlled temperature is cheap since computers can manage the temperature and burning speed, reducing labor costs and efforts (MIT, 2018). There is little research investigating the performance of a single RHA as a soil additive, where RHA was produced at controlled temperature and used as a secondary cementitious material with its natural form.

The key objective of the present study is to examine the influence of controlled burn and as-obtained RHA on the geotechnical properties of A-2-4 type soil. The present investigation is essential to inspire the application of an enormous quantity of RHA as a cement substitute for constructing the different civil infrastructures, particularly in rice-producing countries. A series of laboratory tests were performed, including standard Proctor compaction tests, California bearing ratio (CBR) tests, unconfined compressive strength (UCS) tests, consolidated-drained (CD) triaxial compression tests, and scanning electron microscopy (SEM) test on soil addition with $0 \%, 5 \%, 10 \%$, and $15 \%$ of RHA considering 7 days of moist curing. The effects of various percentages of controlled burn RHA on compactability, bearing capacity, unconfined compressive strength, shear strength, and microstructure of soil are illustrated with discussions.

\section{Materials and methods}

This investigation used SM or A-2-4 type soil and as-obtained controlled burn RHA for specimen preparation. The soil sample was collected from Handa Area, Tsu City, Mie prefecture in Japan, and readymade RHA was collected from the Make Integrated Technology (M.I.T.) company, Osaka, Japan. The major properties of soil and RHA are shown in Table 1. The particle size distribution curve of soil and RHA samples is available in other studies (Nahar et al., 2021). According to the United States Department of Agriculture (USDA) classification system of soil particle size, the soil sample comprises approximately $29 \%$ coarse sand $(0.50-1.00$ $\mathrm{mm}), 36 \%$ medium sand $(0.25-0.50 \mathrm{~mm}), 19 \%$ fine sand $(0.10-$ $0.25 \mathrm{~mm}), 4 \%$ very fine sand $(0.05-0.10), 9 \%$ silt $(0.002-0.05 \mathrm{~mm})$ and $3 \%$ clay $(<0.002 \mathrm{~mm})$. Texturally, the soil is silty sand. The plasticity index $(\mathrm{PI}=7.8 \%)$ indicates the less cohesiveness of soil hence low swell and low expansive potential. The rice husk ash production process was operated in a factory building of M.I.T. Company using an industrial machine device. Only methanol solid fuel was used to ignite the rice husk, then it incinerated by itself. A computer controlled the incineration. About $150 \mathrm{~kg}(15-20 \%)$ of RHA was produced from $800-1000 \mathrm{~kg}$ rice husk. The RHA sample contains $1 \%$ coarse $(0.50-1.00 \mathrm{~mm}), 13 \%$ medium $(0.25-0.50$ $\mathrm{mm}), 63 \%$ fine $(0.10-0.25 \mathrm{~mm})$, and $6 \%$ very fine particles.

All current research experiments were performed at the Experimental Station on Engineering Materials, Faculty of Bioresources, Mie University, Japan. A series of standard Proctor compaction tests, CBR test, unconfined compression strength tests, CD triaxial compression tests were conducted according to Japanese Industrial Standards (JIS) and Japanese Geotechnical Society (JGS) (Table 2). SEM tests were also performed for the microstructural change detection of the specimens.

The combinations of soil and RHA were prepared by taking the mixing percentage of soil with $0 \%$ (control), $5 \%, 10 \%$, and $15 \%$ of RHA content. Three similar specimens for each mix type were prepared and tested for performing a CBR test, UCS test, and triaxial compression test. Soil and the required amount of RHA were manually mixed thoroughly in a big bowl with plastic gloves, and then water was mixed gradually into the dry admixtures. Lower than $2 \%$ from the measured optimum moisture content (OMC) from the compaction tests was added as the required water content of the soil-RHA combinations. All prepared CBR (unsoaked condition), UCS, and triaxial and SEM test specimens were moist cured for 7 days. Each testing procedure is described below.

\section{Standard proctor compaction test method}

The Standard Proctor compaction test was performed for measuring the OMC and maximum dry density (MDD) of control and soil-RHA combinations. The specimens of soil-RHA admixtures were compressed manually in a $10 \mathrm{~cm}$ diameter cylindrical and $1000 \mathrm{~cm}^{3}$ volume compaction mold with a collar and a base. The admixtures were compacted into three layers, giving 25 blows per layer using a $2.5 \mathrm{~kg}$ rammer through a falling height of $30 \mathrm{~cm}$. Approximately $551.8 \mathrm{KJ} / \mathrm{m}^{3}$ was applied as compaction energy for each specimen.

\section{California bearing ratio test method}

The soil-RHA mix types were compacted in a CBR mold with a bottom plate, spacer disc, and mold extension. The diameter and height of the CBR mold were $15 \mathrm{~cm}$ and $17.5 \mathrm{~cm}$, respectively. The admixtures were tamped into three layers with 67 blows per layer using an automated rammer with a mass of $4.5 \mathrm{~kg}$, a diameter of $5.0 \mathrm{~cm}$, and a falling height of $45.0 \mathrm{~cm}$.

Table 1. Properties of soil and rice husk ash used in the study.

\begin{tabular}{clc} 
Particles & Parameters & Values \\
Soil particle & Optimum water content $\left(\mathrm{W}_{\text {opt. }}\right)$ & $17.50 \%$ \\
& Maximum dry density $\left(\gamma_{\text {dry max }}\right)$ & $1.696 \mathrm{~g} / \mathrm{cm}^{3}$ \\
& Specific gravity $(\rho \mathrm{s})$ & $2.7 \mathrm{~g} / \mathrm{cm}^{3}$ \\
& Sand $(75 \mu \mathrm{m}-2 \mathrm{~mm})$ & $88 \%$ \\
& Silt $(5-75 \mu \mathrm{m})$ & $9 \%$ \\
& Clay $<5 \mu \mathrm{m}$ & $3 \%$ \\
& Uniformity coefficient, $\mathrm{C}_{\mathrm{u}}$ & 9.84 \\
& Curvature coefficient, $\mathrm{C}_{\mathrm{c}}$ & 1.02 \\
& Liquid limit, LL & $37.5 \%$ \\
& Plastic limit, $\mathrm{PL}$ & $29.7 \%$ \\
& Plasticity index, PI & $7.8 \%$ \\
& USCS classification & $\mathrm{SM}$ \\
AASHTO classification & $\mathrm{A}-2-4(0)$ \\
RHA particle & Burning temperature & $650{ }^{\circ} \mathrm{C}-700^{\circ} \mathrm{C}$ \\
& Burning duration & $27 \mathrm{hours}$ \\
Average particle size & $0.001 \mathrm{to} 0.3 \mathrm{~mm}$ \\
Specific gravity & $2.12 \mathrm{~g} / \mathrm{cm}^{3}$ \\
Silica (SiO2) & $91.10 \%$ \\
Carbon dioxide $\left(\mathrm{CO}{ }_{2}\right)$ & $4.35 \%$ \\
Potassium oxide $\left(\mathrm{K}_{2} \mathrm{O}\right)$ & $2.40 \%$ \\
Calcium oxide $(\mathrm{CaO})$ & $0.57 \%$ \\
Alumina $\left(\mathrm{Al}_{2} \mathrm{O}_{3}\right)$ & $0.03 \%$ \\
Others & $1.55 \%$ \\
\hline
\end{tabular}

USCS, Unified Soil Classification System; AASHTO, American Association of State Highway and Transportations Officials.

Table 2. Conducted laboratory tests with followed standards.

Name of the experiment Standard followed

Test method for soil compaction using a rammer

JIS A 1210:2010

Test methods for the California bearing ratio JIS A 1211:2010 of soils in the laboratory

Method for unconfined compression test of soils JIS A 1216:2010 Triaxial compression test of soil JGS 0520-0524:2010 
The CBR values were calculated for the penetration depth of $2.5 \mathrm{~mm}$ using Eq. (1).

$$
\text { CBR value }(\%)=\frac{\text { Load strength }}{\text { Standard load strength }} \times 100
$$

\section{Unconfined compressive strength test method}

The UCS specimens of soil-RHA combinations were compressed in the mold with a diameter of $5.0 \mathrm{~cm}$ and a height of 12.5 $\mathrm{cm}$. Each specimen was compacted into three layers, and each layer was tamped by 20 blows using a $4.9 \mathrm{~cm}$ diameter rammer, which had a mass of $1.0 \mathrm{~kg}$ with a falling height of $30 \mathrm{~cm}$. The stress-strain relationship, UCS values, and elasticity of the specimens were determined from the stress-strain curve, where the strain was plotted on the $\mathrm{X}$-axis and stress on the Y-axis. In the stress-strain curve, the peak value from stress $(\sigma)$ is the UCS $\left(q_{u}\right)$. The deformation modulus $\left(E_{50}\right)$ of the specimens were measured by eliminating the initial and final non-linearities of the stressstrain curve, and it was calculated from the following equation:

$$
E_{50}=\frac{\frac{q_{u}}{2}}{\varepsilon_{50}} / 10
$$

where $E_{50}$ is the modulus of deformation in $\mathrm{MPa}, \varepsilon_{50}$ is the compressive strain, and $q_{u}$ is the maximum value from stress in $\mathrm{kPa}$.

\section{Triaxial test method}

The triaxial test specimens were prepared using the same mold and techniques of UCS specimen preparation. The three confining pressures $(50 \mathrm{kPa}, 100 \mathrm{kPa}, 150 \mathrm{kPa})$ were applied in this experiment. The cohesion $(c)$ and angle of internal friction $(\varphi)$ of triaxial test results were calculated using graphical and mathematical methods. The Mohr-Coulomb failure criterion was followed as a graphical technique, where specimens fail due to a critical combination of normal stress and shear stress. The equation for the failure envelope line is as follows:

$\tau_{f}=c+\sigma_{f} \tan \varphi$

where, $\tau_{f}$ is the shear stress of the failure plane and, $\sigma_{f}$ is normal stress on the failure plane. The following equation was also used to calculate the cohesion $(c)$ and angle of internal friction $(\varphi)$ :

$\sigma_{a}=\sigma_{r} \tan ^{2}(45+\phi / 2)+2 c \tan (45+\varphi / 2)$

where $\sigma_{a}$ is the major, and $\sigma_{r}$ the minor effective principal stress.

\section{Scanning electron microscopy test method}

The SEM images of soil-RHA combinations in magnification 1000 times were selected to understand the microstructural changes of particles in the specimens. The SEM test samples were collected from triaxial test specimens in this investigation.

\section{Results and discussion}

\section{Compaction characteristics}

The OMC and MDD of soil with $0 \%, 5 \%, 10 \%$, and $15 \%$ RHA combinations were measured from the compaction curves in Figure 1A. The variations of OMC and MDD of soil-RHA admixtures showed that the OMC increased, while MDD decreased with the increment of RHA in the soil mix (Figure 1B). The OMC of the untreated soil was $17.5 \%$, and with the increase of RHA content, the OMC of the treated soil with 5\%,10\%, and 15\% RHA was $20.0 \%, 24.0 \%$, and $28.2 \%$, respectively. This happened due to the absorption of a massive amount of water by the surplus fine particles of microporous RHA in the soil-RHA mixtures (Singh, 2018). The MDD of the control specimen was $1.696 \mathrm{~g} / \mathrm{cm}^{3}$, and with the addition of RHA, the decreasing percentage of MDD for 5\% RHA $\left(1.545 \mathrm{~g} / \mathrm{cm}^{3}\right), 10 \%$ RHA $\left(1.436 \mathrm{~g} / \mathrm{cm}^{3}\right)$, and $15 \%$ RHA $(1.334$ $\mathrm{g} / \mathrm{cm}^{3}$ ) was $8.9 \%, 15.3 \%$, and $21.3 \%$ correspondingly. The declining tendency of MDD may be clarified by the difference of specific gravity between soil $\left(2.70 \mathrm{~g} / \mathrm{cm}^{3}\right)$ and RHA $\left.2.12 \mathrm{~g} / \mathrm{cm}^{3}\right)$. The RHA particles act as a filler in soil pore spaces due to their lower specific gravity compared to soil (Alhassan, 2008).

\section{California bearing ratio test results}

The load-penetration curves of soil with $0 \%, 5 \%, 10 \%$, and $15 \%$ RHA combinations are shown in Figure 2A. The calculated
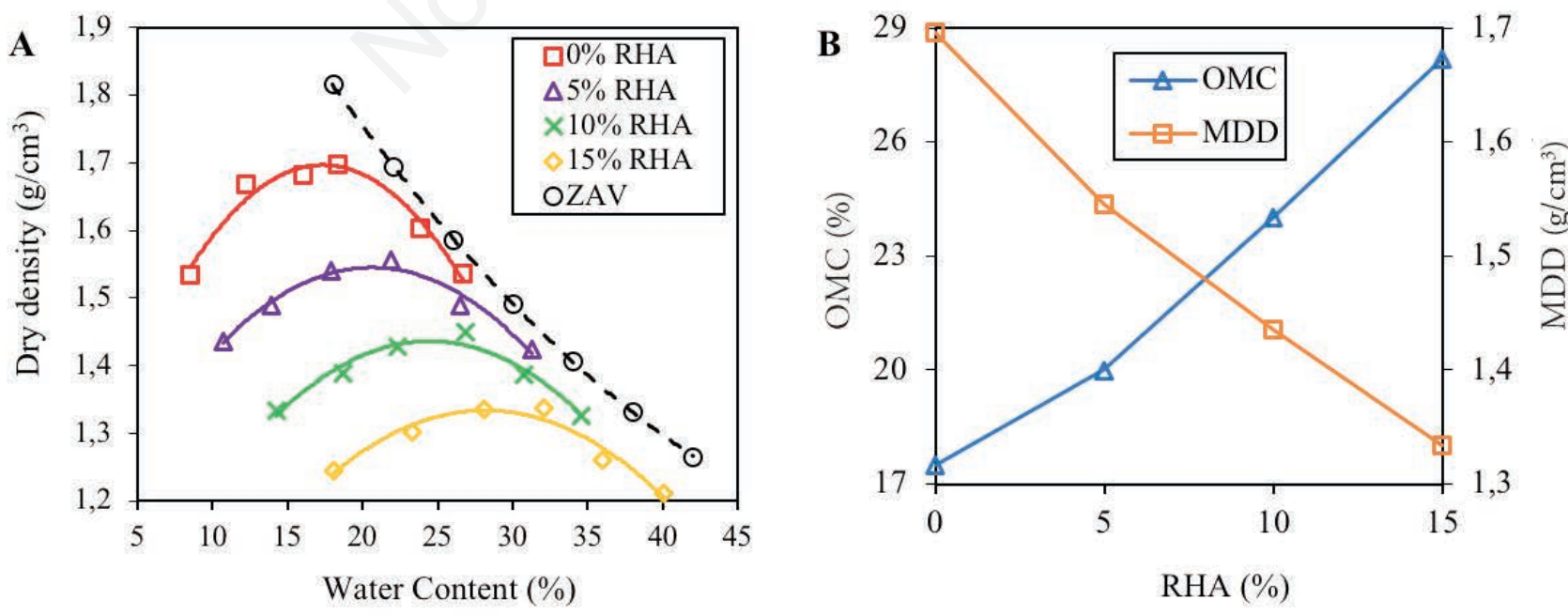

Figure 1. (A) Compaction curves, zero air void (ZAV); and (B) variation of optimum moisture content (OMC) and maximum dry density (MDD) of soil with $0 \%, 5 \%, 10 \%, 15 \%$ rice husk ash (RHA). 
CBR value of control was $42.2 \%$. The CBR value increased with $5 \%$ RHA and afterward declined at $10 \%$ and $15 \%$ RHA mixed soil. Soil with a 5\% RHA combination showed the highest CBR value (58.9\%), 10\% RHA (47.0\%) also exhibited an improvement of CBR value compared to control, and the CBR value for $15 \%$ RHA
(36.3\%) displayed the lower than control. The progress of CBR value for 5\% RHA specifies the pozzolanic reactions among the substantial amount of reactive $\mathrm{SiO}_{2}$, and a negligible amount of $\mathrm{Al}_{2} \mathrm{O}_{3}$, and $\mathrm{CaO}$ with water in the soil (Sarkar et al., 2012). The reduction in $\mathrm{CBR}$ value after adding $15 \%$ RHA may bedue to the
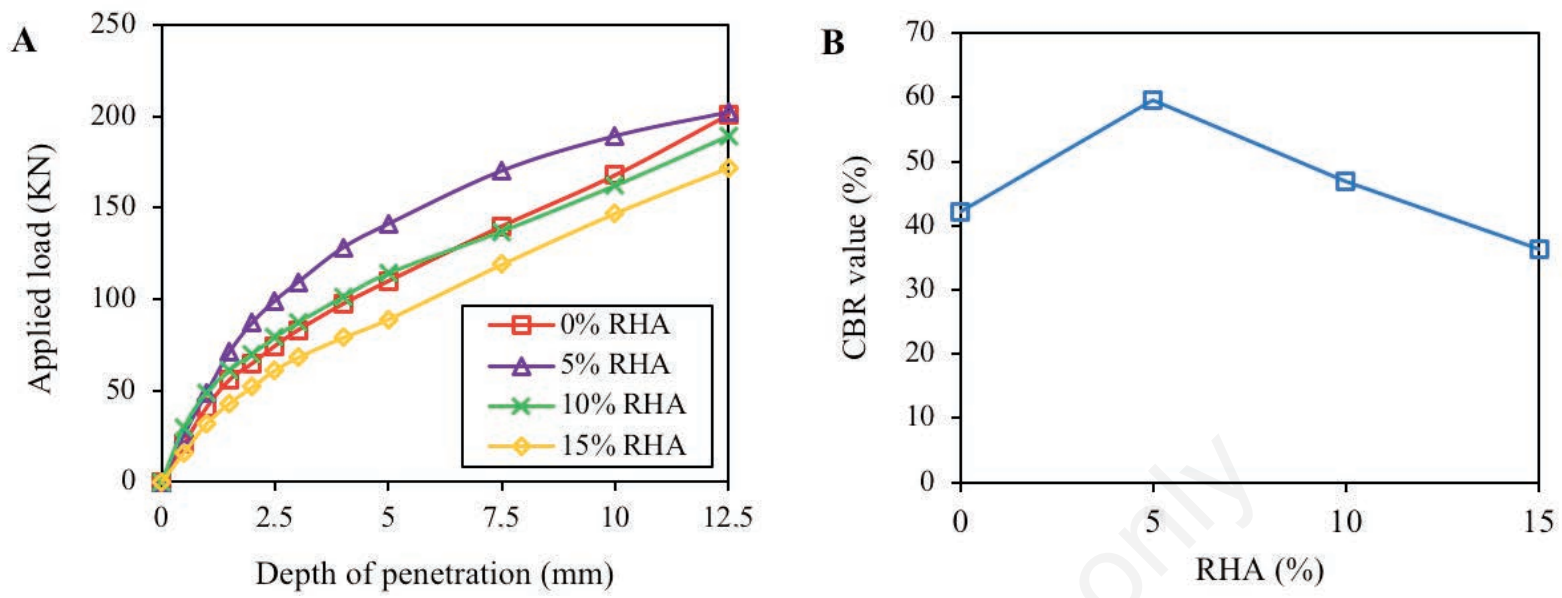

Figure 2. (A) Load penetration curves; and (B) California bearing ratio (CBR) value of soil with $0 \%, 5 \%, 10 \%, 15 \%$ rice husk ash (RHA).
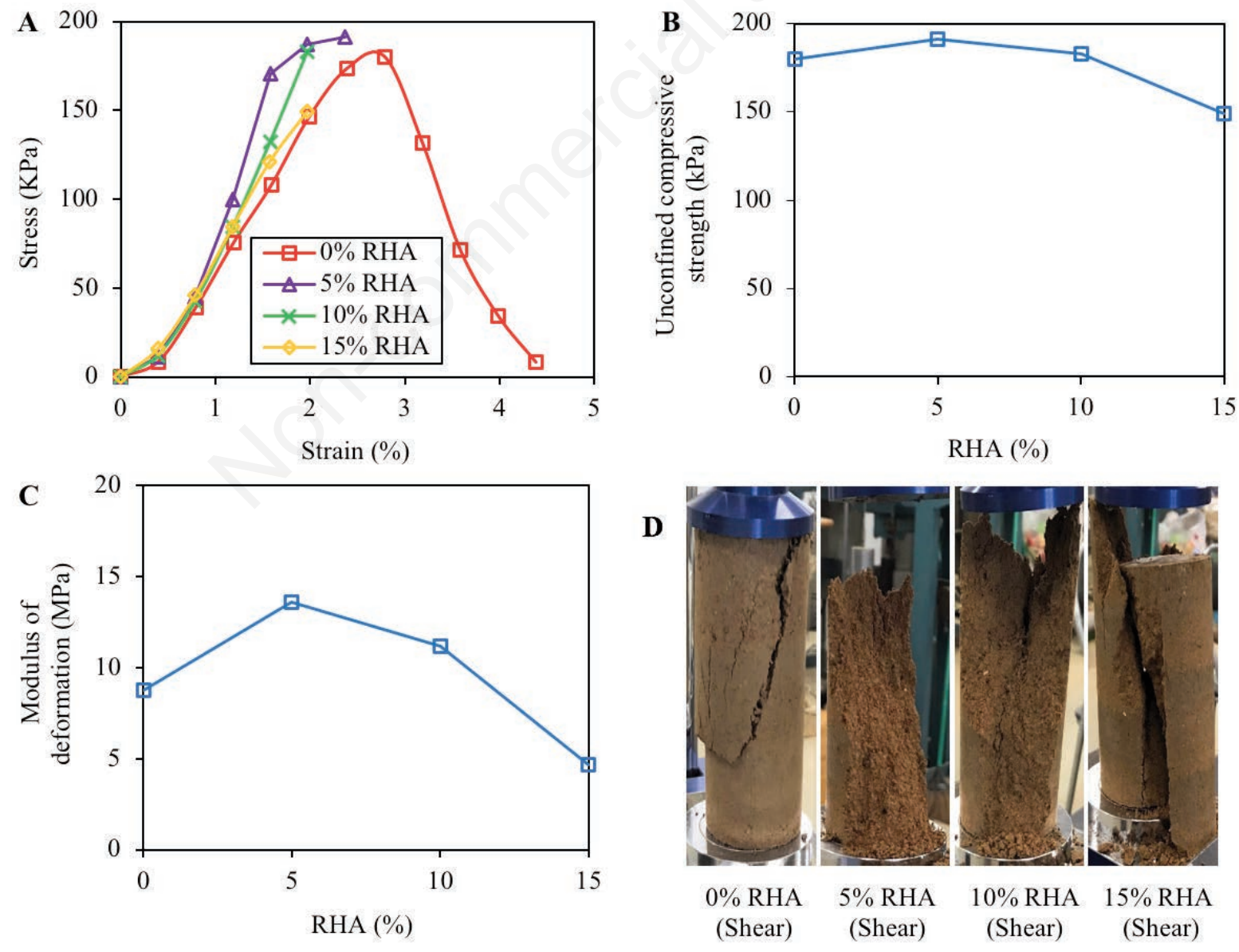

Figure 3. (A) Stress-strain relationship; (B) Unconfined Compressive strength (UCS); (C) Modulus of deformation ( $E_{50}$ ); (D) Failure mode of soil with $0 \%, 5 \%, 10 \%, 15 \%$ rice husk ash (RHA). 
extra RHA weakening the bonding between soil and pozzolanic materials in the mixtures (Alhassan, 2008).

\section{Unconfined compressive strength test results}

The stress-strain relationship curves of soil with $0 \%, 5 \%, 10 \%$, and $15 \%$ RHA mix types are shown in Figure 3A. Each curve of this figure illustrates that the compressive stress increased with displacement until reaching the topmost value, then delivered a softening behaviour. It is noticed from Figure $3 \mathrm{~B}$ and $\mathrm{C}$ that the addition of RHA showed an improvement of UCS value and modulus of deformation $\left(E_{50}\right)$. Likewise, the results from the CBR test, the soil with 5\% RHA showed the highest strength and elasticity (UCS $=190.9 \mathrm{kPa}$ and $E_{50}=13.6 \mathrm{MPa}$ ) among all soil-RHA combinations. After the addition of $10 \%$ RHA, the UCS $(183.1 \mathrm{kPa})$ and $E_{50}(11.1 \mathrm{MPa})$ values decreased compared to 5\% RHA, but these values are higher than the control specimen (UCS $=180.0 \mathrm{kPa}$ and $\left.E_{50}=8.7 \mathrm{MPa}\right)$. Soil with $15 \%$ RHA showed lower UCS (149.2 $\mathrm{kPa})$ and $E_{50}(4.7 \mathrm{MPa})$ values than control. Shear failure mode was observed from the failure plane of all soil-RHA specimens. The addition of RHA exhibits a slight change in the properties from ductile to brittle nature (Figure 3D). Likewise, the improvement of soil bearing capacity with 5\% RHA, the pozzolanic reactions, and mechanical interconnections of the particles of soil and RHA enhanced the UCS value of this soil-RHA combination.

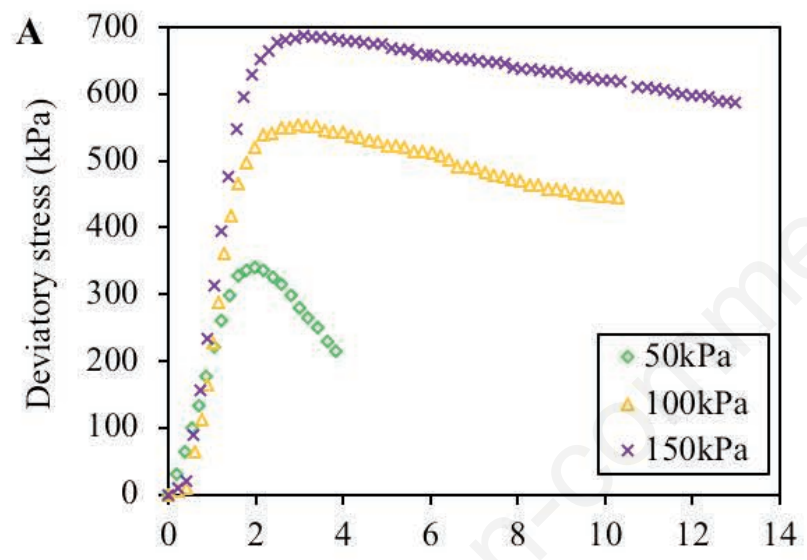

Axial strain (\%)

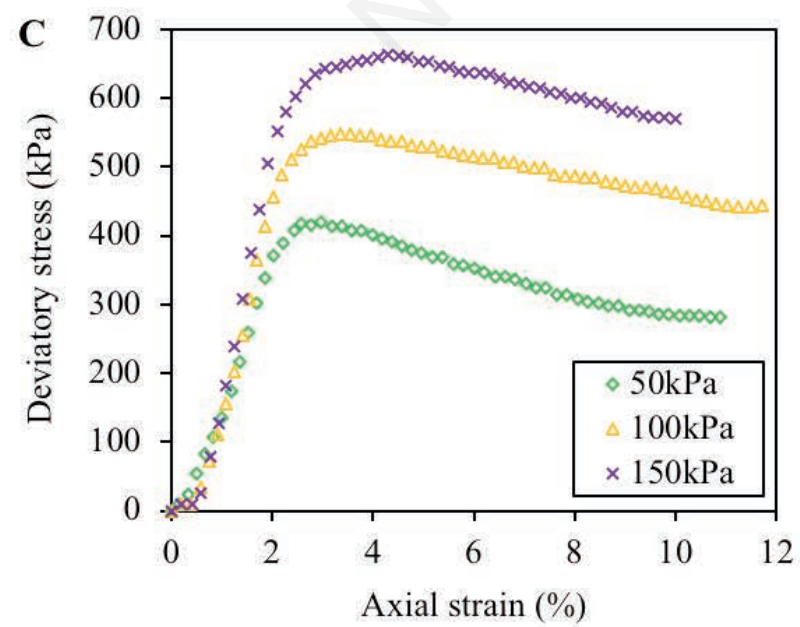

\section{Triaxial test results}

The association between axial strain $\left(\varepsilon_{a}\right)$ and deviatory stress $\left(\Delta \sigma=\sigma_{a^{-}} \sigma_{r}\right)$ of soil with $0 \%, 5 \%, 10 \%$, and $15 \%$ RHA combinations are exhibited in Figures 4A-4D. The figures showed a common trend of stress-strain relationship, initially stress increased with the increase of strain, and after getting the topmost value, the stress followed softening behaviour. The angle of internal friction and cohesion of the control specimen was $32^{\circ}$ and $76 \mathrm{kPa}$, respectively. It is noticeable from Figures $5 \mathrm{~A}$ that soil with $5 \%$ and $10 \%$ RHA combinations improved the cohesion (c). The cohesion values for 5\%, $10 \%$, and $15 \%$ RHA were $85,80,72 \mathrm{kPa}$, correspondingly, whereas the angle of internal friction values was $34^{\circ}, 33^{\circ}$, and $20^{\circ}$ accordingly (Figures 5A-5B). Likewise, in the UCS and CBR test results, soil with 5\% RHA achieved the highest shear strength properties, and soil with $10 \%$ RHA reached the second-highest strength. The soil with 15\% RHA had lower cohesion and angle of internal friction values than the control specimen. All triaxial test specimens also exhibited shear failure patterns. The mechanism of pozzolanic reactions and strength development in different soil-RHA combinations have been explained in the CBR results section.

\section{Scanning electron microscopy test results}

The SEM test results of soil with $0 \%, 5 \%, 10 \%$, and $15 \%$ RHA are shown in Figures 6A-6D. The untreated soil had a smooth and
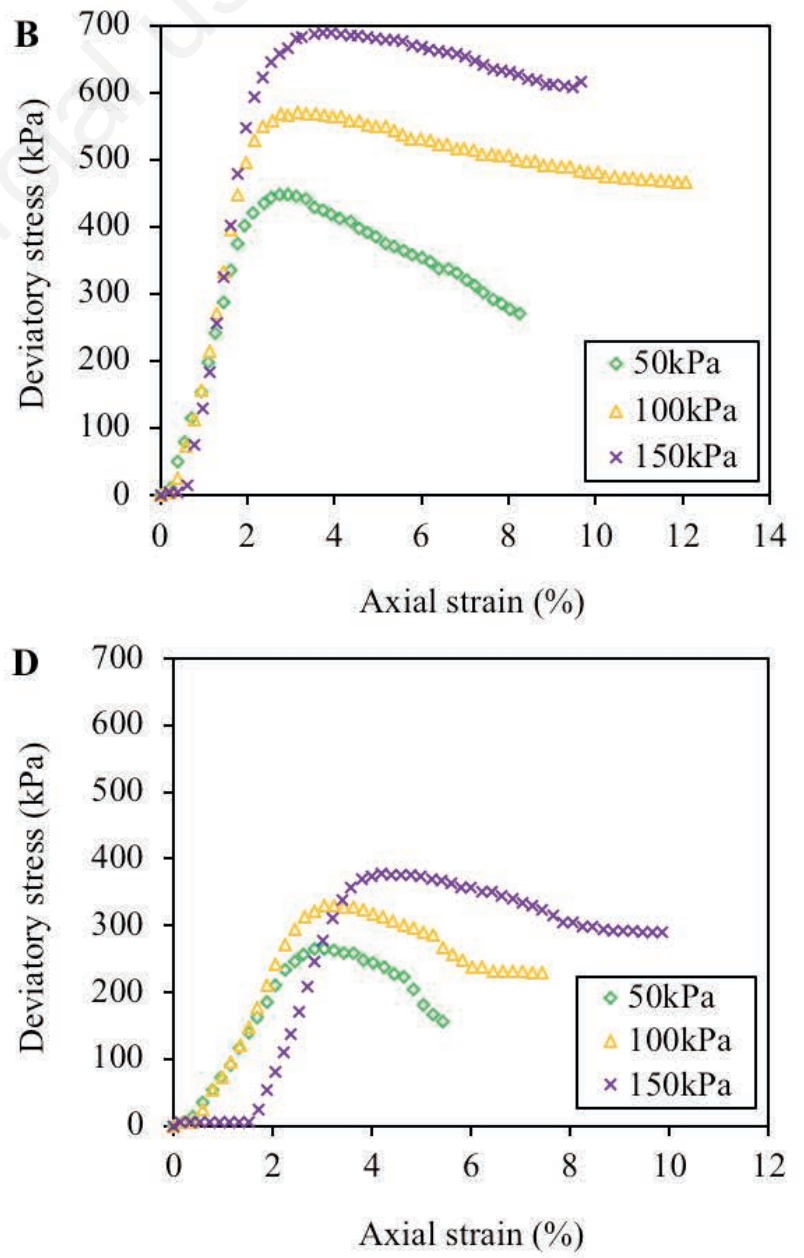

Figure 4. The axial strain $\left(\varepsilon_{a}\right)$ and deviatory stress $(\Delta \sigma)$ relationship of soil with (A) $0 \%$ rice husk ash (RHA); (B) $5 \%$ RHA; (C) $10 \%$ RHA; and (D) $15 \%$ RHA. 
rough surface together with no spherical particles (Figure 6A). After adding RHA in the soil, the mechanical interconnection (Ramesh and Manjunatha, 2020) and pozzolanic reaction between the soil and RHA particles (Sarkar et al., 2012) altered the microstructure of the soil. The surface roughness of treated soil increased with the increment of RHA content due to increased pore spaces compared to the control specimen. Soil with 5\% RHA exhibited the best mechanical linkage between the particles of soil and RHA with pozzolanic reactions, resulting in the best microstructural and strength development (Figure 6B). Further
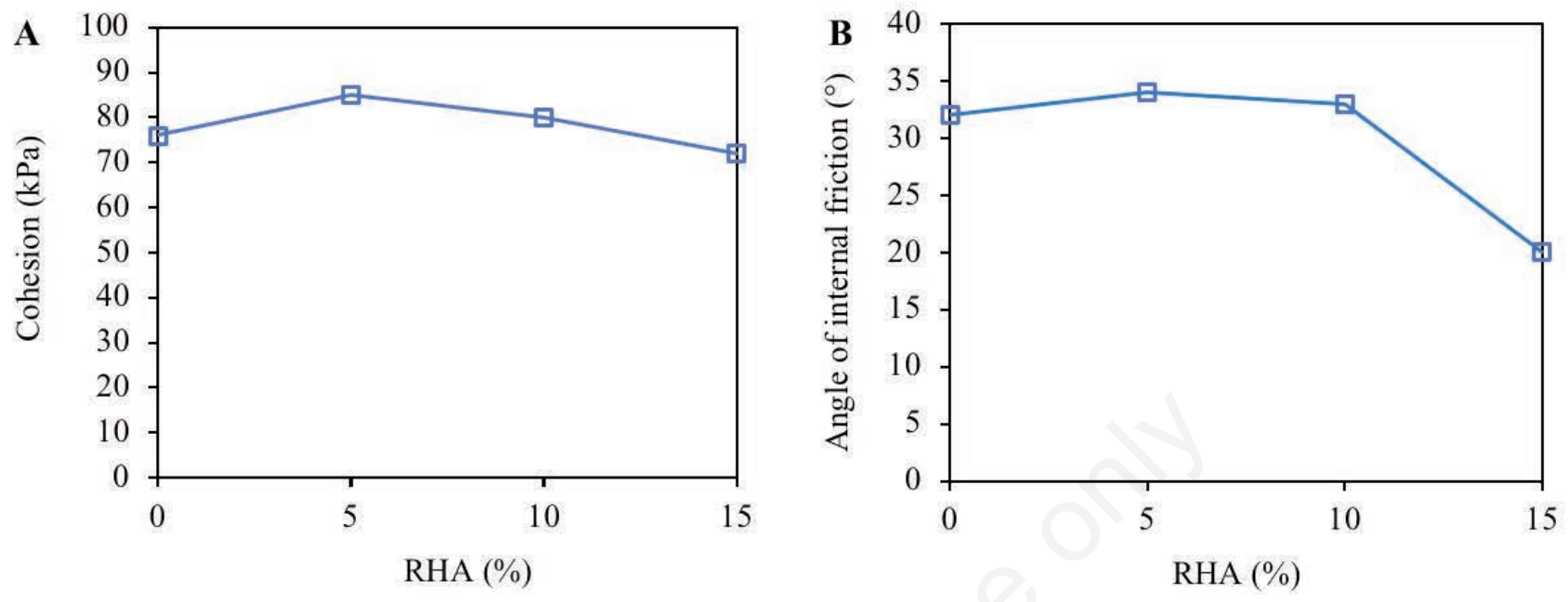

Figure 5. (A) Cohesion (c); and (B) angle of internal friction of $(\varphi)$ soil with $0 \%, 5 \%, 10 \%, 15 \%$ rice husk ash (RHA).
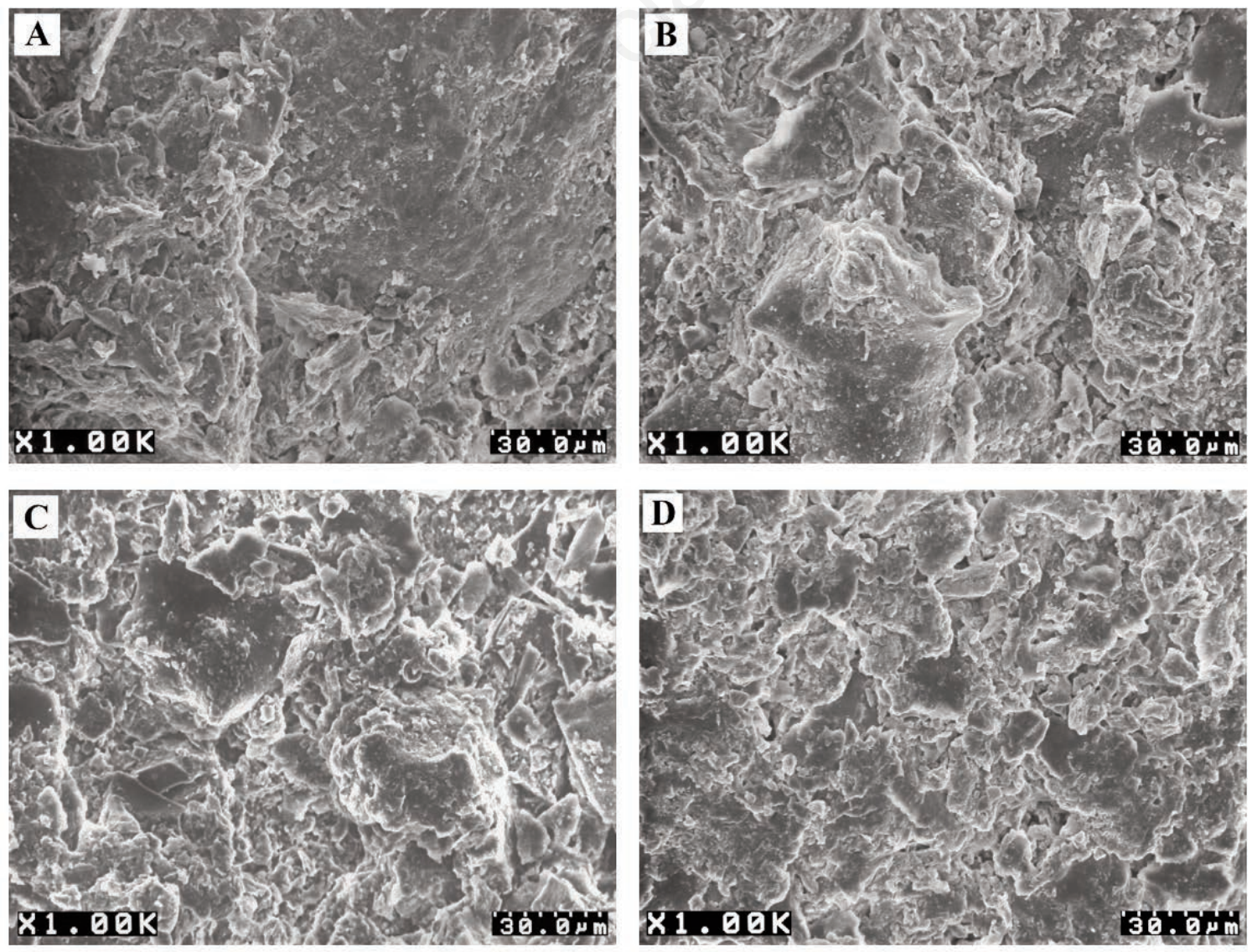

Figure 6. Scanning electron micrograph of soil with (A) 0\% rice husk ash (RHA); (B) 5\% RHA; (C) 10\% RHA; and (D) 15\% RHA with $1000 \times$ magnification. 
addition of RHA increased the pore spaces, which inhibited the interlocking and pozzolanic reaction between soil and RHA particles, achieving less microstructural and strength development in the soil (Figures 6C-6D).

\section{Conclusions}

From the experimental investigation on the addition of burnt RHA at controlled temperature with soil, it can be concluded that soil with $0 \%, 5 \%, 10 \%$, and $15 \%$ of RHA combinations influenced the compaction characteristics, bearing capacity, UCS, shear strength and microstructure of soil. The OMC increased, but MDD decreased with the increasing amount of RHA. The initial addition of $5 \%$ RHA with soil showed the best improvement of geotechnical properties, and then these values declined with the increase of RHA. An increase of UCS value $(190.9 \mathrm{kPa})$ and deformation modulus (13.6 MPa) for 5\% of RHA was $6.0 \%$ and $56.3 \%$ respectively compared to the control specimen (UCS $=180.0 \mathrm{kPa}$ and $\mathrm{E}_{50}=8.7 \mathrm{MPa}$ ). $\mathrm{CBR}$ value increased by about $39.5 \%$ for the combination of soil with $5 \%$ RHA $(58.9 \%)$, while the CBR of control was $42.2 \%$. The increasing percentage of cohesion $(85 \mathrm{kPa})$ and angle of internal friction $\left(34^{\circ}\right)$ of $5 \%$ RHA with soil was $11.8 \%$ and $6.3 \%$.

The results showed the improvement of geotechnical properties of soil by utilization of RHA, which recommended that soil with 5\% RHA can be used as a construction material for rural roads and pedestrian roads which can reduce construction costs and ensure environmental sustainability.

\section{References}

Adhikary S., Jana K. 2016. Potentials of rice husk ash as a soil stabilizer. International J. Latest Res. Eng. Technol. 2:40-2.

Ayininuola G.M., Olaosebikan O.I. 2013. Influence of rice husk ash on soil permeability. Transnatl. J. Sci. Technol. 3:29-33.

Al-Hasnawi A.A.K., Al-Hydary I.A.D. 2019. The devitrification kinetics of transparent silica glass prepared by gel-casting method. Matéria (Rio de Janeiro). 24.

Alhassan M. 2008. Potentials of rice husk ash for soil stabilization. Assumption Univ. J. Tech. 11:246-50.

Chandrasekhar S.A.T.H.Y., Satyanarayana K.G., Pramada P.N., Raghavan P., Gupta T.N. 2003. Review processing, properties and applications of reactive silica from rice husk- an overview. J. Mater. Sci. 38: 3159-68.

Della V.P., Kühn I., Hotza D. 2002. Rice husk ash as an alternate source for active silica production. Mater. Lett. 57:818-21.

FAOSTAT. 2020. Crops-production/yield quantities of rice, paddy in world + (Total): 1994-2018. Food and Agriculture Organization of the United Nations. Available from: http://www.fao.org/faostat/en/\#data/QC/visualize

Hwang C.L., Chandra S. 1996. The use of rice husk ash in concrete. pp 184-234 in Waste mater. used in concr. Manuf.
William Andrew Publishing.

Jain A., Choudhary A.K., Jha J.N. 2020. Influence of rice husk ash on the swelling and strength characteristics of expansive soil. Geotech. Geol. Eng. 38:2293-302.

JIS A 1210, 2010. Test method for soil compaction using a rammer. Japanese Industrial Standard, Guidance and Basic - Soil Test, The Japanese Geotechnical Society (in Japanese), pp. 71-78.

JIS A 1211, 2010. Test method for the California Bearing Ratio (CBR) of soils in laboratory. Japanese Industrial Standard, Guidance and Basic - Soil Test, The Japanese Geotechnical Society (in Japanese), pp. 79-90.

JIS A 1216, 2010. Method for unconfined compression test of soils. Japanese Industrial Standard, Guidance and Basic - Soil Test, The Japanese Geotechnical Society (in Japanese), pp. 151-158.

JGS 0520-0524, 2010. Triaxial compression test of soil, Guidance and Basic - Soil Test (in Japanese), The Japanese Geotechnical Society, pp. 135-150.

MIT, 2018. What is plant-based (fir shell) silica? Difference from conventional technology (in Japanese). Available from: https://www.mit-corp.biz/business/biosilica/

Murthy B.S., Babu G.S., Srinivas A. 2002. Analysis of bearing capacity improvement using micropiles. Proc. Instit. Civil Eng.-Ground Improv. 6:121-8.

Nahar N., Hossain Z., Tamaki N. 2021. Optimum utilization of rice husk ash waste for ground improvement. Int. Agric. Eng. J. 30:1-10.

Okafor F.O., Okonkwo U.N. 2009. Effects of rice husk ash on some geotechnical properties of lateritic soil. Niger. J. Technol. 28:46-52.

Pode R. 2016. Potential applications of rice husk ash waste from rice husk biomass power plant. Renew. Sustain. Energy Rev. 53:1468-85.

Rahman Z.A., Ashari H.H., Sahibin A.R., Tukimat L., Razi I.W.M. 2014. Effect of rice husk ash addition on geotechnical characteristics of treated residual soil. Am.-Euras. J. Agric. Environ. Sci. 14:1368-77.

Ramesh H.N., Manjunatha B.V. 2020. Justification of strength properties of microstructural changes in the black cotton soil stabilized with rice husk ash and carbide lime in the presence of sodium salts. SN Appl. Sci. 2:1-12.

Rathan R.R., Banupriya S., Dharani R. 2016. Stabilization of soil using rice husk ash. Int. J. Comput. Eng. Res. 6:43-50.

Roy S., Bhalla S.K. 2017. Role of geotechnical properties of soil on civil engineering structures. Res. Environ. 7:103-9.

Sarkar G., Islam M.R., Alamgir M., Rokonuzzaman M. 2012. Interpretation of rice husk ash on geotechnical properties of cohesive soil. Global J. Res. Eng. 12.

Singh B. 2018. Rice husk ash. pp. 417-460 in Waste and supplementary cementitious materials in concrete. Woodhead Publishing.

Thomas B. S. 2018. Green concrete partially comprised of rice husk ash as a supplementary cementitious material - A comprehensive review. Renew. Sustain. Energy Rev. 82:3913-23. 